\title{
Reliability of Water Distribution Networks
}

\author{
Alaa Hisham Naguib, Mohamed Hassan Abdel Razik, Mohamed Ali Fergala, Sherien Ali Elagroudy \\ Public Works Department, Faculty of Engineering, \\ Ain Shams University, \\ Cairo, Egypt
}

\begin{abstract}
Water distribution network reliability is the ability of the system to supply the required demand with sufficient pressure at normal and abnormal conditions. A methodology is developed for the assessment and enhancement of water distribution networks reliability. Upgrade scenarios are introduced to increase the network reliability, then optimization analysis is carried out for the selection of the optimum upgrade scenario according to a predefined objective function. A case study of Monshaat Al Qanater is conducted to illustrate the application of proposed methodology. It can be concluded that single supply pipeline should be avoided. Network Loops should be balanced as possible in terms of hydraulic capacity. Increasing number of working pumps and percentage of standby pumping capacity improve network reliability. Network reliability can also be improved by, reducing the break rate by preventive maintenance of the system components or using high quality of pipe materials and pumps.
\end{abstract}

Keywords- Water Network, Reliability, Availability, Mechanical Reliability, Hydraulic Reliability, Water Network Assessment.

\section{INTRODUCTION}

Water network reliability is an indirect measure of customer satisfaction about the level of water supply service. Reliability is generally overlooked in the design of water distribution networks. Current design guidelines are generally concerned with system configuration, valve distribution, demand and pressure requirements rather than system performance in case failure of any component.

There are many definitions for water networks reliability in the literature:

- Kaufmann et al. [1] defined reliability as the probability that the system performs its specified tasks under specified conditions during a specified time.

- Cullinane et al. [2] defined reliability as the ability of the system to provide service with an acceptable level of interruption in spite of abnormal conditions.

- Goulter et al. [3] defined reliability as the ability of the system to meet the demands that are placed on it where demands are specified in terms of amount of flows to be supplied and the range of pressures at which those flow rates must be provided.

- Al-Zahrani et al. [4] defined reliability as the ability of the network to deliver water to consumers in the required quantity and quality at suitable pressure head.

In the current study, water supply system reliability is defined as ability of the system to supply the required demand with sufficient pressure under normal and abnormal conditions. Normal conditions mean common operation with no failure of any component of the network, while abnormal conditions mean the network operation with one or more components out of service. Reliability is measured by a value from zero to $100 \%$ representing the ratio of hydraulic performance between abnormal and normal conditions. System reliability of $100 \%$ means the system is fully functional under break of any system component.

The following definitions are adopted in the study:

- Hydraulic reliability, which describes the performance of the system to satisfy the required water demand.

- Component reliability is defined as the probability that a component has no failure during its life time.

- Mechanical reliability, which measures the effect of component failure on the system performance, mechanical reliability depends on both hydraulic reliability and component reliability.

- Network/System reliability, is the minimum mechanical reliability of all system components.

For example, a single supply pipeline would have zero hydraulic reliability but $98 \%$ mechanical reliability if its probability of failure is $2 \%$. If there are many cases of failure, then the network reliability is defined as the minimum mechanical reliability.

\section{A. Reliability Analysis Approaches}

Over the last few decades, several methods have been developed for the assessment of water systems reliability. However, there is no widely accepted approach or methodology introduced for water network reliability analysis. Ostfeld [5] classified the approaches to assessment of water systems reliability into three groups: analytical (connectivity), simulation (hydraulic) and heuristic (entropy) approaches.

\section{1) Analytical Approach}

Analytical approaches deal with the layout of water distribution network, which is associated with the probability that a given network keeps physically connected, given its component reliabilities. These approaches are linked to concepts of connectivity and reachability that are not based on hydraulic simulations. One of the methods used to evaluate network reliability is Minimum Cut Set Method, where cut set are defined as a set of failed elements whose failure cause the isolation of node/s from the system, without taking into consideration the effect of these failed elements on the network or the condition of other elements.

\section{2) Simulation Approach}

Simulation approaches deal with the hydraulic reliability and availability. Thus, they analyses the hydraulic performance of the network, i.e. a suppling of the required quantities and qualities of water at adequate pressure to the appropriate locations at any given time. Therefore, these approaches rely heavily on hydraulic models and require very good information about the network layout and operation, including the records related to the component failures, these 
are the most widely research approaches, nowadays, this methodology uses this approach for the reliability analysis.

There are two methods for hydraulic analysis of water networks: Demand Driven Analysis (DDA) and Pressure Dependent Demand (PDD).

In hydraulic modelling of water systems, in most cases demand driven analysis is assumed where the demand the satisfied regardless to the pressure. This model may produce unrealistic results especially during failure condition of the network. Another approach of modelling is pressure dependent demand where, if the pressure is above a threshold value, it is thought that the node demand is not influenced by pressure. The node demand is reduced when the pressure is reduced below the pressure threshold and the demand is zero when the pressure is reduced to zero. This approach is more realistic, and many functions have been developed by many researchers [6].

Goulter et al [7] introduced a reliability method based on relationship between flow and pressure. If demand is met but at reduced flow, then the network reliability decreases. Also, if the pressure satisfies the minimum required threshold value but the demand is not satisfied then the network reliability decreases. In case of both pressure and demand are not met the network reliability is greatly reduced.

\section{3) Heuristic Approach}

Heuristic approaches do not measure the performance of the water system directly they assess other attributes such as energy or power used which are expected to have strong correlation with reliability, as another method for measuring network reliability. Many approaches has been developed such as Entropy-Based Method by K. Awamah et al [8], Network Resilience by Prasad et al [9], Performance Index by Dziedzic et al. [10].

\section{B. Pipe Failure Modelling}

Component reliability, is defined as the probability that a component has no failure during an interval from time 0 to time $T$ [11]. It best describes non-repairable components, where after failure they have to be replaced. But, in water networks most components are repairable, so component failure is best described as component availability.

Availability $(A)$ is the percentage of time where a component is functionally operating, while the component is considered Unavailable $(U)$ when it is in failure or repair status [12].
Pipe failure models are statistical models which use historical data of pipe failures to detect their failurse patterns, then use these patterns to predict in probability of pipe failure future. Statistical models can be classified into two main categories according to Kleiner et al. [13], Liu et al. [14] and Scheidegger et al. [15]:

\section{1) Deterministic models}

These models are developed from historical data of component failure in order to predict future failure rate (e.g. number of failures per year or failure rate or time to next failure).

Shamir et al. [16] used regression analysis to acquire a break prediction model that relates a pipes breakage to the exponent of its age. This model is used to forecast break rates to group of homogenous pipes based on historical data.

Walski et al. [17] update the exponential model by adding two factors to the model, the first factor is for the historical previous breaks in the pipes based on that broken pipes are more likely to be broken again, the second factor is the effect of different diameter sizes in the break pattern.

Clark et al. [18] developed two regression models. The first model to predict the life time between installation and the first break, and the second model is to predict the number of breaks after the first break, It was concluded that a pipe with early failure will suffer more break event more than that pipe that has a late failure.

Kleiner et al. [19] proposed a multi-variate exponential model, which can be used on pipes with homogenous properties that affect their deterioration rates.

Parvizsedghy et al. [20] developed a model for assessment of water pipelines deterioration. Deterioration factors were divided into three main groups: physical, environmental, and operational. The model showed that pipe age is the dominant parameter for predicting the failure rates.

\section{2) Probabilistic models}

Models that explicitly and quantitively consider most of the covariates in the analysis which make these models more general for estimating future breakage rates of water pipes.

Cox [21] introduced a general form of the prediction hazards model which is used to estimate the time to next failure.

Goulter et al. [22] and Su et al. [23] used Poisson probability distribution to determine the probability of failure of individual pipes. 
Andreou et al. [24] developed a vector covariant hazard function during the analysis of their failure data, they observed that the time intervals between first three consecutive failures had an ascending order. After the third failure, these intervals seemed to be constant. So, the developed model was characterized by two stages, the first stage where fewer breaks take place and represented by the proportional hazard function, and the second stage more frequent breaks which was represented by a Poisson distribution model.

Constantine et al. [25] developed a time-dependent Poisson distribution model with average break rate depending on pipe age, the used process is also known as a Weibull process, because the resulting cumulative distribution in this process is equivalent to the Weibull cumulative distribution function.

Kleiner et al. [26] developed computer application IWARP (Individual Water mAin Renewal Planner), which is a tool to analyses the failure records of break patterns of individual water pipelines. I-WARP is based on the assumption that breaks on an individual pipe occur as a nonhomogeneous Poisson process.

Scheidegger et al. [27] developed a model based on the assumptions that the time to the first failure is modeled by Weibull distribution and all the successive failures are modeled as exponential distribution. These assumptions result in an inflexible failure rate that cannot represent deterioration over time and is only partly manipulated by the previous failures.

\section{METHODOLOGY}

This research describes the adopted methodology for calculation of network reliability and the selection of best applicable upgrade scenario to improve network reliability. A case study for applying this methodology is illustrated and the outcome conclusions and recommendation are presented to be furtherly taken into consideration during design new water networks.

The methodology is divided into 7 steps as described in the flow chart presented in Figure 1. A detailed calculations procedure for each step are explained in order to illustrate the methodology. The methodology steps are as below:

Step 1: Build Hydraulic Model.

Step 2: Calculate Component Availability.

Step 3: Calculate Hydraulic Reliability.

Step 4: Calculate Mechanical Reliability.

Step 5: Calculate Network Reliability.

Step 6: Define Upgrade Scenarios.

Step 7: Optimization Analysis.

\section{A. Step 1: Build Hydraulic Model}

The first step is to prepare a hydraulic model that simulates the real network conditions in case of no failure (Base Scenario), and in cases of failure of any preselected critical component. Pressure Dependent Demand (PDD) approach is used in the hydraulic analysis as it is more appropriate for evaluation of customer satisfaction, which is illustrated in Eq. 1.

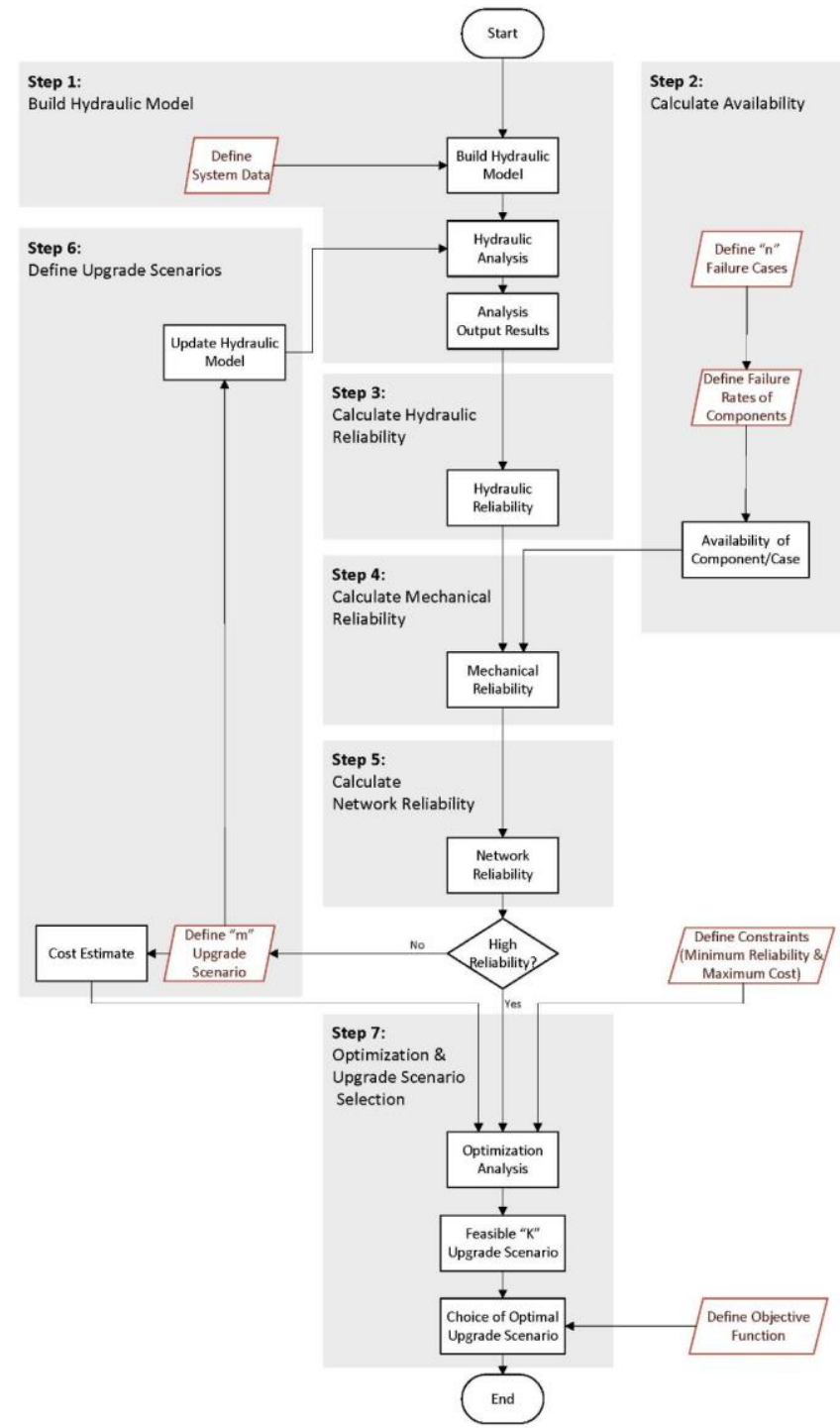

Figure 1 Flowchart of the Adopted Methodology for Water Network Reliability Analysis

$\frac{Q_{a j}}{Q_{r j}}=\left\{\begin{array}{cc}0 & H_{a j} \leq 0 \\ \left(\frac{H_{a j}}{H_{r j}}\right)^{\infty} & 0<H_{a j}<H_{r j} \\ 1 & H_{a i} \geq H_{r i}\end{array}\right.$

Where;

$Q_{a j}=$ Actual Flow at node $\mathrm{j}$.

$Q_{r i}=$ Required Flow at node $\mathrm{j}$.

$H_{a j}=$ Actual Pressure at node j.

$H_{r j}=$ Reference Pressure or threshold Pressure Value at node $\mathrm{j}$ to supply full required flow at node $\mathrm{j}$.

$\alpha=$ Exponent of the pressure and discharge relationship.

\section{B. Step 2: Calculate component Availability}

Deterministic models are used to describe component availability for pipes and pumps, as described below: 
1) Pipe Availability

The probability of pipe failure is derived from the failure rate (expressed as number of breaks per unit length of pipe per unit time). Pipe availability depends on historical break data, time to repair and pipeline length as presented in Eq. 2 to 4 .

$A=1-P_{f}$

$P_{f}($ Pipe $)=\frac{\lambda_{\text {pipe }} * L * T R}{365}$

$\lambda_{\text {pipe }}=\frac{\text { No.of Breaks per Year }}{\text { Pipe Length }(\mathrm{km})}$

Where;

$A=$ Component Availability.

$P_{f}=$ Probability of failure

$\lambda_{\text {pipe }}=$ Break Rate (break. km-1. year-1) which depends on historical data

$L=$ Pipe length $(\mathrm{km})$.

$T R=$ Time of Repair in days.

\section{2) Pump Availability}

Pumps availability depends on number of working pumps, pump break rate, time to repair and percentage of standby pumps as presented in Eq. 5 to Eq. 7.

$$
\begin{gathered}
P_{f}(\text { Pump })=\frac{\lambda P_{u m p}{ }^{* F} \cdot T R}{365} \\
\lambda_{P_{\text {ump }}}=\frac{\text { noof times out of service }}{\text { no.of years }}
\end{gathered}
$$

$$
F=\frac{\text { No.of Working Pumps }}{\text { Total No.of Pumps [Working }+ \text { standby) }}
$$

Where;

$\lambda_{\text {Pump }}=$ Pump Break Rate (break. year-1).

$F=$ Pump Break Rate Correction Factor, taking into consideration the percentage of standby pumps. As the percentage of standby pumps increases, the operation time decreases, and pump break rate decreases by the factor F. For example, in case of 2 working +1 standby pump, the operation time of each pump is reduced from 12 to 8 months per year, and consequently, pump break rate decreases by $67 \%$.

\section{Step 3: Calculate Hydraulic Reliability}

The simulation method of reliability is used to get the performance of the water network under normal and abnormal conditions. The equations developed by Goulter et al [7], are used to measure the hydraulic reliability as indicated by Eq. 8 and Eq. 9:

$N D_{H}=\sum_{j=1}^{n} q_{j} \cdot H_{\min }-\sum_{j=1}^{n} q_{⿷}^{j} \cdot H_{a}^{j}$
Hydraulic Reliability $\left(R_{H}\right)=\frac{N D_{H}}{\sum_{\tilde{i}=1}^{n} q_{\tilde{i}} \cdot H_{\min }}$

Where;

$N D_{H}=$ Hydraulic Network Deficit

$\mathrm{n}=$ No. of nodes

$q_{\tilde{f}}=$ Required Flow at node $\mathrm{j}$

$H_{\min }=$ Minimum threshold pressure

$q_{n}^{j}=$ Actual Flow at node $\mathrm{j}$

$H_{\pi}^{j}=$ Actual Pressure at node $\mathrm{j}$ If $H_{n}^{\tilde{j}}>H_{\text {min }}$ then $H_{n}^{\tilde{j}}=H_{\text {min }}$

$R_{H}=$ Hydraulic Reliability

D. Step 4: Calculate Mechanical Reliability

Mechanical Reliability depends on both hydraulic reliability and component availability. For example, if the hydraulic reliability is dropped to $40 \%$ for $20 \%$ of the year, mechanical reliability is estimated by the area under the curve in Figure 2 which is $88 \%$, as expressed by Eq. 10. The mechanical reliability is calculated for each failure case for each scenario.

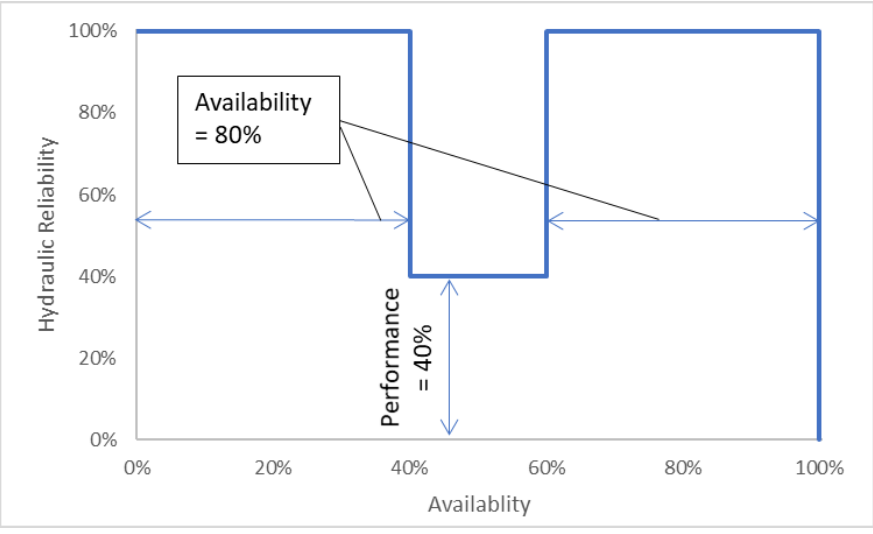

Figure 2 Calculation of Mechanical Reliability

$R_{M}=1-\left[\left(1-R_{H}\right) *(1-A)\right]$

Where;

$R_{M}=$ Mechanical Reliability

$R_{H}=$ Hydraulic Reliability

$A=$ Availability of component

\section{E. Step 5: Calculate Network Reliability}

The Network Reliability is the minimum mechanical reliability in the studied failure cases for each scenario.

The network reliability is evaluated with relation to a predefined target minimum reliability, then upgrade scenarios proposed to overcome deficiencies in the current base scenario.

\section{F. Step 6: Define Upgrade Scenarios}

Upgrade scenarios are made to increase network reliability. These scenarios differ from network to another depending on its components and configurations. For each upgrade scenario, the hydraulic analysis is carried out for the calculation of network reliability as steps 1 to 5 . Construction 
cost is estimated for each upgrade scenario. Examples for upgrade scenarios are illustrated below:

- Add parallel pipes or close a pipe loop.

- Increasing the number working or standby pumps.

- Add tanks.

- Reduction of the break rate by applying regular maintenance and using high quality components.

G. Step 7: Optimization Analysis

In order to select the most feasible upgrade scenarios optimization analysis is carried out, as following:

a) Define objective function which can be:

- Maximize Network Reliability.

- Minimize Upgrade Cost.

- Maximum reliability to cost ratio, through Cost Benefit Analysis (CBA).

b) Define constrains which can be:

- Minimum Network Reliability.

- Maximum Available Budget.

c) Identify the Feasible Zone.

d) Selection of the most feasible upgrade scenario.

\section{CASE StUdy: MonshaAT Al QANATER WATER DISTRIBUTION SYSTEM}

\section{A. Step 1: Build Hydraulic Model}

Monshaat Al Qanater - Egypt network serves a group of 12 scattered villages from a water treatment plant of capacity $80,000 \mathrm{~m}^{3} / \mathrm{d}$. The water network node diagram is illustrated in Figure 3 .
Pipes and Junctions data are shown in TABLE 1 and TABLE 2 .

TABLE 1 MONSHAAT AL QANATER PIPE DATA

\begin{tabular}{|c|c|c|c|c|c|}
\hline $\begin{array}{c}\text { Pipe } \\
\text { Label }\end{array}$ & $\begin{array}{c}\text { Diameter } \\
(\mathrm{mm})\end{array}$ & $\begin{array}{c}\text { Length } \\
(\mathrm{m})\end{array}$ & $\begin{array}{c}\text { Pipe } \\
\text { Label }\end{array}$ & $\begin{array}{c}\text { Diameter } \\
(\mathrm{mm})\end{array}$ & $\begin{array}{c}\text { Length } \\
(\mathrm{m})\end{array}$ \\
\hline P-1 & 1,000 & 286 & P-17 & 400 & 2,624 \\
\hline P-2 & 900 & 499 & P-18 & 600 & 1,822 \\
\hline P-3 & 900 & 3,503 & P-19 & 600 & 3,879 \\
\hline P-4 & 900 & 6,126 & P-20 & 400 & 3,103 \\
\hline P-5 & 500 & 6,930 & P-21 & 400 & 3,833 \\
\hline P-6 & 500 & 5,786 & P-23 & 400 & 6,418 \\
\hline P-7 & 500 & 994 & P-24 & 600 & 2,246 \\
\hline P-8 & 600 & 2,926 & P-25 & 500 & 3,934 \\
\hline P-9 & 900 & 2,056 & P-26 & 500 & 2,456 \\
\hline P-10 & 152 & 183 & P-27 & 500 & 133 \\
\hline P-11 & 500 & 1,363 & P-28 & 250 & 121 \\
\hline P-12 & 250 & 348 & P-30 & 300 & 188 \\
\hline P-13 & 900 & 2,067 & P-31 & 250 & 549 \\
\hline P-14 & 800 & 8,491 & P-32 & 250 & 471 \\
\hline P-15 & 250 & 1,433 & P-33 & 400 & 280 \\
\hline P-16 & 700 & 2,776 & & & \\
\hline
\end{tabular}

All pipes are assumed to have a break rate of 0.2 break/km/year and time to repair 2 days.

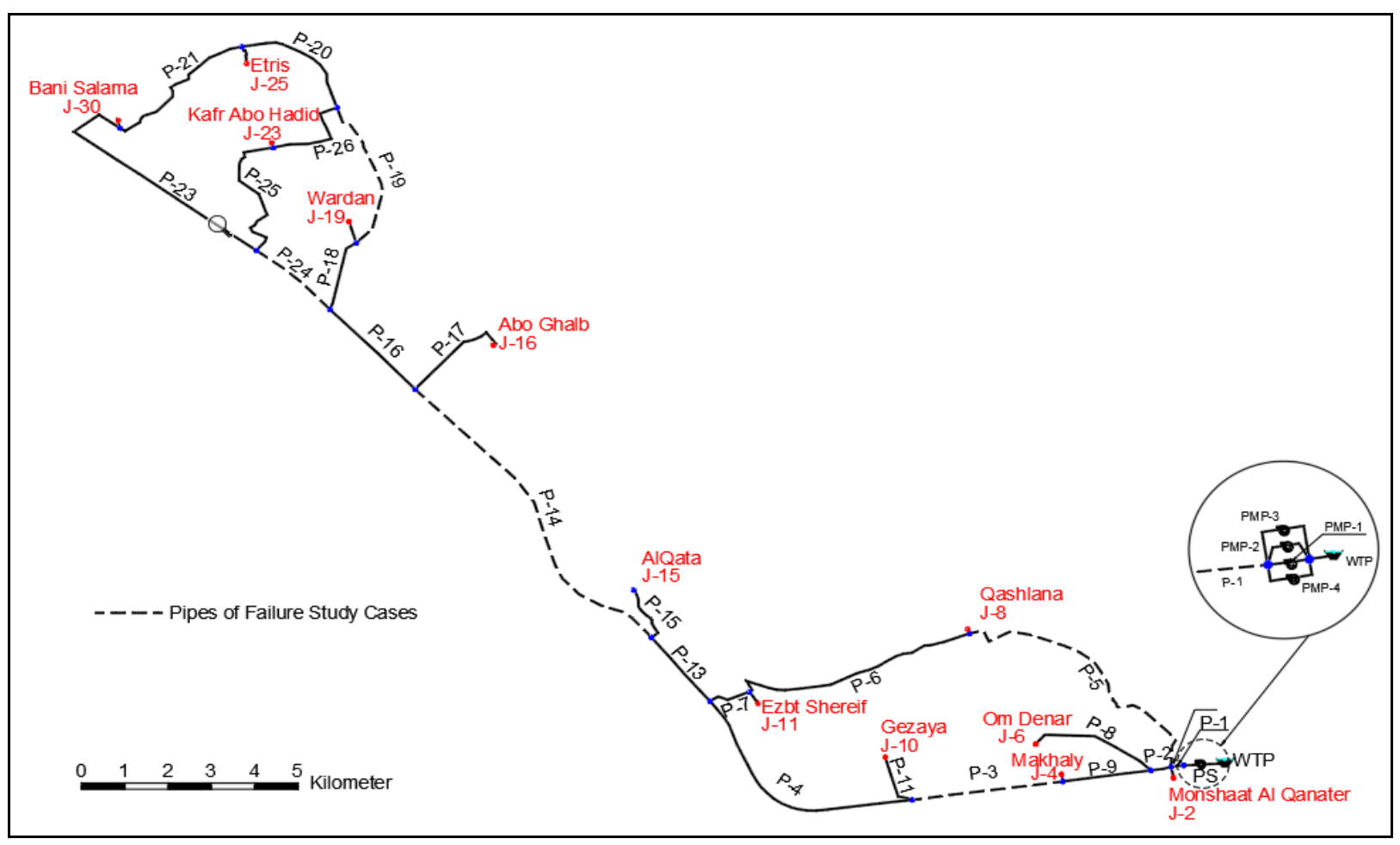

Figure 3 Monshaat Al Qanater Main Water Supply Network 
TABLE 2 MONSHAAT AL QANATER JUNCTION DATA

\begin{tabular}{|c|c|c|c|c|}
\hline $\begin{array}{c}\text { Junction } \\
\text { Label }\end{array}$ & Village Name & $\begin{array}{c}\text { Elevation } \\
(\mathrm{m})\end{array}$ & $\begin{array}{c}\text { Demand } \\
(\mathrm{L} / \mathrm{s})\end{array}$ & $\begin{array}{c}\text { Pressure }^{\mathrm{a}} \\
(\mathrm{bar})\end{array}$ \\
\hline $\mathbf{J - 2}$ & $\begin{array}{c}\text { Monshaat Al } \\
\text { Qanater }\end{array}$ & 23.00 & 172.0 & 5.9 \\
\hline $\mathbf{J - 4}$ & Makhaly & 18.84 & 10.0 & 6.2 \\
\hline $\mathbf{J - 6}$ & Om Denar & 15.82 & 162.0 & 6.5 \\
\hline $\mathbf{J - 8}$ & Qashlana & 14.64 & 10.0 & 6.5 \\
\hline $\mathbf{J - 1 0}$ & Gezaya & 20.88 & 224.0 & 5.4 \\
\hline $\mathbf{J - 1 1}$ & Ezbt Shereif & 17.66 & 10.0 & 5.9 \\
\hline $\mathbf{J - 1 5}$ & AlQata & 20.04 & 35.0 & 5.3 \\
\hline $\mathbf{J - 1 6}$ & Abo Ghalb & 17.60 & 90.0 & 5.0 \\
\hline $\mathbf{J - 1 9}$ & Wardan & 10.51 & 13.0 & 5.7 \\
\hline $\mathbf{J - 2 3}$ & Kafr Abo & 13.50 & 136.0 & 5.2 \\
\hline $\mathbf{J - 2 5}$ & Hadid & 8.88 & 50.0 & 5.3 \\
\hline $\mathbf{J - 3 0}$ & Bani Salama & 13.12 & 88.0 & 5.0 \\
\hline
\end{tabular}

a. The target minimum pressure is assumed to be 5 bar at each village.

The distribution network is supplied from the water treatment plant by 4 working pumps and 2 standby pumps each of flow $250 \mathrm{~L} / \mathrm{s}$ and head $60 \mathrm{~m}$, with assumed 5 break/year and time to repair 2 days.

\section{B. Step 2: Availability}

The identified failure cases in this case study are as following and shown in Figure 3:

- Pipes P-1, P-3, P-5, P-14, P-19 and P-24.

- Pump (PMP-1).

The availability of each failed pipe is calculated and shown in TABLE 3, while the availability of the pump is 98.17\% (160.8 Hours out service per year).

\section{TABLE 3 PIPES AVAILABILITY}

\begin{tabular}{|c|c|c|c|c|}
\hline $\begin{array}{c}\text { Cases of } \\
\text { Failure }\end{array}$ & $\begin{array}{c}\text { Diameter } \\
(\mathrm{mm})\end{array}$ & $\begin{array}{c}\text { Length } \\
(\mathrm{m})\end{array}$ & $\begin{array}{c}\text { Availability } \\
(\%)\end{array}$ & $\begin{array}{c}\text { Hours out of } \\
\text { Service per } \\
\text { year }\end{array}$ \\
\hline P-1 & 1,000 & 286 & $99.97 \%$ & 2.4 \\
\hline P-3 & 900 & 3,503 & $99.62 \%$ & 33.6 \\
\hline P-5 & 500 & 6,930 & $99.24 \%$ & 67.2 \\
\hline P-14 & 800 & 8,491 & $99.07 \%$ & 81.6 \\
\hline P-19 & 600 & 3,879 & $99.57 \%$ & 38.4 \\
\hline P-24 & 600 & 2,246 & $99.75 \%$ & 21.6 \\
\hline
\end{tabular}

\section{Step 3: Hydraulic Reliability}

Hydraulic analysis for each failure case is carried out and to calculate the hydraulic reliability using Pressure Dependent Demand, as shown in TABLE 4.
TABLE 4 BASE SCENARIO HYDRAULIC RELIABILITY

\begin{tabular}{|c|c|}
\hline Cases of Failure & Hydraulic Reliability \\
\hline P-1 & $0.00 \%$ \\
\hline P-3 & $43.35 \%$ \\
\hline P-5 & $99.03 \%$ \\
\hline P-14 & $62.30 \%$ \\
\hline P-19 & $97.70 \%$ \\
\hline P-24 & $96.53 \%$ \\
\hline PMP-1 & $86.33 \%$ \\
\hline
\end{tabular}

D. Step 4 \& 5: Mechanical and Network Reliability

After calculating both the availability and the hydraulic reliability, the mechanical reliability of each failure case of the base scenario can be conducted as shown in TABLE 5 .

TABLE 5 BASE SCENARIO MECHANICAL RELIABILITY

\begin{tabular}{|c|c|c|c|}
\hline $\begin{array}{c}\text { Cases of } \\
\text { Failure }\end{array}$ & Availability (\%) & $\begin{array}{c}\text { Hydraulic } \\
\text { Reliability (\%) }\end{array}$ & $\begin{array}{c}\text { Mechanical } \\
\text { Reliability (\%) }\end{array}$ \\
\hline P-1 & $99.97 \%$ & $0.00 \%$ & $99.969 \%$ \\
\hline P-3 & $99.62 \%$ & $43.35 \%$ & $99.783 \%$ \\
\hline P-5 & $99.24 \%$ & $99.03 \%$ & $99.993 \%$ \\
\hline P-14 & $99.07 \%$ & $62.30 \%$ & $99.649 \%$ \\
\hline P-19 & $99.57 \%$ & $97.70 \%$ & $99.990 \%$ \\
\hline P-24 & $99.75 \%$ & $96.53 \%$ & $99.991 \%$ \\
\hline PMP-1 & $98.17 \%$ & $86.33 \%$ & $99.750 \%$ \\
\hline \multicolumn{2}{|c}{ Minimum } & $\mathbf{9 9 . 6 4 9 \%}$ \\
\hline
\end{tabular}

From TABLE 5, it can be concluded that the network reliability of the base scenario is $99.649 \%$ (minimum value of the Mechanical Reliability) which corresponds to the failure case P-14. So, in order to improve the network reliability upgrade scenarios are imposed. It should be taken in consideration that during proposing upgrade scenarios that the network reliability is governed by failure case P-14 so during preparing upgrade scenarios, upgrades to overcome the failure case of P-14 should have the highest priority in order to increase the network reliability.

\section{E. Step 6: Upgrade Scenarios}

The upgrade scenarios differ from one network to another, upgrades are used to increase the networks reliability to be able to satisfy the water demand requirements at abnormal condition. Figure 4 shows the imposed upgrade components. And TABLE 6 shows the defined upgrade scenarios of Monshaat Al Qanater.

\section{TABLE 6 MONSHAAT AL QANATER DEFINED UPGRADE} SCENARIOS

\begin{tabular}{|c|c|c|c|}
\hline $\begin{array}{c}\text { Upgrade } \\
\text { Scenario }\end{array}$ & Description & $\begin{array}{c}\text { Upgrade } \\
\text { Scenario }\end{array}$ & Description \\
\hline S-0 & Base Scenario & S-7 & P-1 \& P-14 \\
\hline S-1 & P-3 & S-8 & P-3 \& P-14 \\
\hline S-2 & P-1 & S-9 & P-5 \& P-14 \\
\hline S-3 & P-1 \& P-3 & S-10 & P-1`, P-3 \& P-14 \\
\hline S-4 & P-5 & S-11 & Add T-1 \\
\hline S-5 & P-1 \& P-5 & S-12 & Add T-1 \& P-14 \\
\hline S-6 & P-14 & S-13 & Add T-1 \& T-2 \\
\hline
\end{tabular}




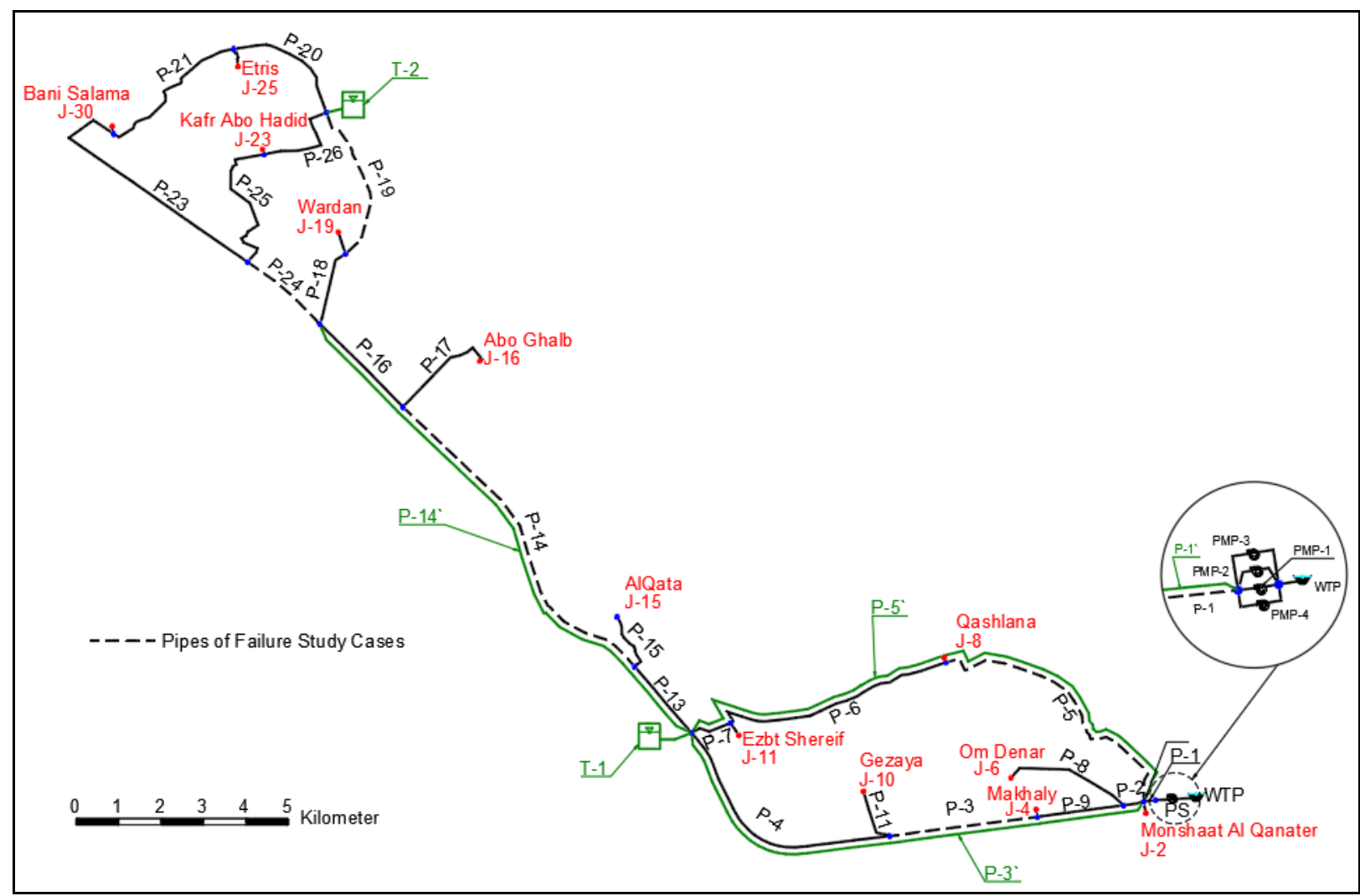

Figure 4 Monshaat Al Qanater Upgrade Components

The reliability analysis for these scenarios are conducted to calculate the network reliability of each upgrade scenario, also the additional cost due to the upgrade is estimated for further optimization analysis of these solutions as shown in TABLE 7.

Also, Figure 5 shows the network reliability and the cost estimate of each upgrade scenario.

From the above analysis it can be concluded that the upgrade scenarios from S-1 to S-5 and S-11 did not improve the network reliability even though an additional components has been added, this is due to that this upgrade scenarios didn't address the issue of failure case P-14 as this case gives the minimum mechanical reliability. So, when applying upgrade scenarios to overcome the failure case P-14 as in S-6 to $\mathrm{S} 13$ (except S-11) it can be seen the resulting improvement in the network reliability.

The failure case P-3 is also crucial where even after improvement to overcome the failure of $\mathrm{P}-14$ the network

TABLE 7 UPGRADE SCENARIOS RELIABILITY ANALYSIS

\begin{tabular}{|c|c|c|c|c|c|c|c|c|c|}
\hline \multirow{2}{*}{$\begin{array}{l}\text { Upgrade } \\
\text { Scenario }\end{array}$} & \multicolumn{7}{|c|}{ Mechanical Reliability of Failure Cases } & \multirow{2}{*}{$\begin{array}{l}\text { Network } \\
\text { Reliability }\end{array}$} & \multirow{2}{*}{$\begin{array}{l}\text { Cost Estimate } \\
\text { (Mil EGP) }\end{array}$} \\
\hline & $P-1$ & $P-3$ & $P-5$ & $P-14$ & $P-19$ & $P-24$ & PMP-1 & & \\
\hline S-0 & $99.969 \%$ & $99.783 \%$ & $99.993 \%$ & $99.649 \%$ & $99.990 \%$ & $99.991 \%$ & $99.750 \%$ & $99.649 \%$ & 0.0 \\
\hline S-1 & $99.969 \%$ & $100 \%$ & $100 \%$ & $99.649 \%$ & $99.999 \%$ & $99.997 \%$ & $99.813 \%$ & $99.649 \%$ & 43.9 \\
\hline S-2 & $100 \%$ & $99.783 \%$ & $99.993 \%$ & $99.649 \%$ & $99.991 \%$ & $99.992 \%$ & $99.756 \%$ & $99.649 \%$ & 1.2 \\
\hline S-3 & $100 \%$ & $100 \%$ & $100 \%$ & $99.649 \%$ & $99.999 \%$ & $99.997 \%$ & $99.818 \%$ & $99.649 \%$ & 45.1 \\
\hline S-4 & $99.969 \%$ & $99.863 \%$ & $100 \%$ & $99.649 \%$ & $99.994 \%$ & $99.993 \%$ & $99.772 \%$ & $99.649 \%$ & 29.0 \\
\hline S-5 & $100 \%$ & $99.863 \%$ & $100 \%$ & $99.649 \%$ & $99.994 \%$ & $99.994 \%$ & $99.777 \%$ & $99.649 \%$ & 30.2 \\
\hline S-6 & $99.969 \%$ & $99.784 \%$ & $100 \%$ & $100 \%$ & $100 \%$ & $99.998 \%$ & $99.801 \%$ & $99.784 \%$ & 40.5 \\
\hline S-7 & $100 \%$ & $99.784 \%$ & $100 \%$ & $100 \%$ & $100 \%$ & $99.999 \%$ & $99.807 \%$ & $99.784 \%$ & 41.7 \\
\hline S-8 & $99.969 \%$ & $100 \%$ & $100 \%$ & $100 \%$ & $100 \%$ & $100 \%$ & $99.868 \%$ & $99.868 \%$ & 84.4 \\
\hline S-9 & $99.969 \%$ & $99.868 \%$ & $100 \%$ & $100 \%$ & $100 \%$ & $99.999 \%$ & $99.824 \%$ & $99.824 \%$ & 69.5 \\
\hline S-10 & $100 \%$ & $100 \%$ & $100 \%$ & $100 \%$ & $100 \%$ & $100 \%$ & $99.873 \%$ & $99.873 \%$ & 85.6 \\
\hline S-11 & $99.993 \%$ & $99.959 \%$ & $99.945 \%$ & $99.649 \%$ & $99.953 \%$ & $99.970 \%$ & $99.835 \%$ & $99.649 \%$ & 20.0 \\
\hline S-12 & $99.994 \%$ & $99.976 \%$ & $99.979 \%$ & $99.942 \%$ & $99.970 \%$ & $99.979 \%$ & $99.939 \%$ & $99.939 \%$ & 60.5 \\
\hline S-13 & $99.996 \%$ & $99.986 \%$ & $100 \%$ & $99.995 \%$ & $100 \%$ & $100 \%$ & $100 \%$ & $99.986 \%$ & 40.0 \\
\hline
\end{tabular}




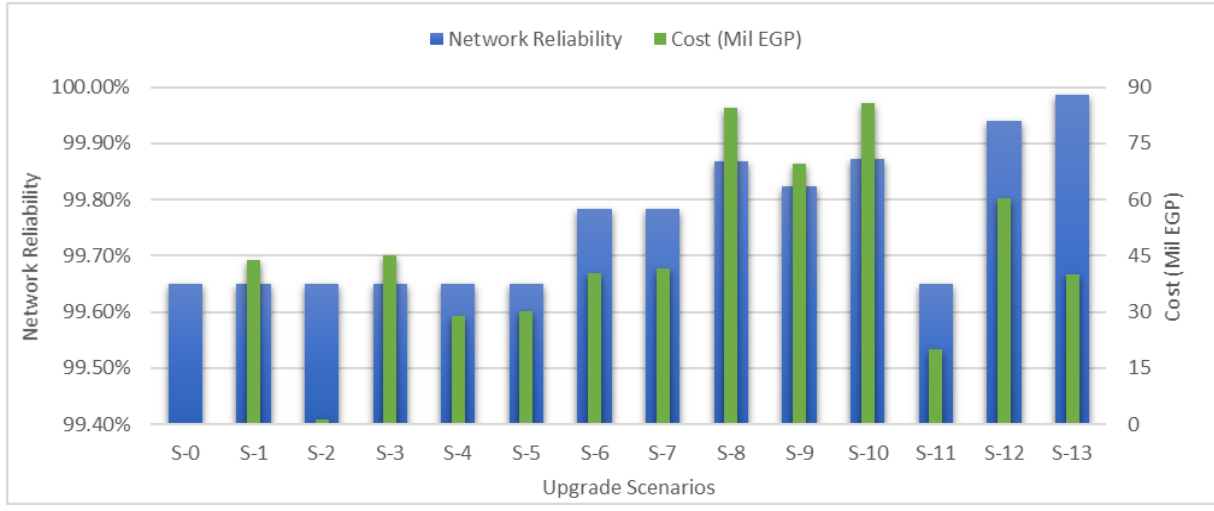

Figure 5 Upgrade Scenarios Network Reliability and Cost Estimate

reliability is increased to $99.784 \%$ in upgrade scenarios S-6 and S-7, even though P-3 is part of a loop its failure was not surpassed by the other loop branch this is due to the uneven balance in the loop system where pipe P-3 is considered the main supplier pipe with a large diameter of $900 \mathrm{~mm}$ and P-5 is a branched pipe to supply the users by the other side of the system and smaller diameter of $500 \mathrm{~mm}$. This can be testified in S-4 or S-5 where an additional pipe is added to P-5 making the loop more balanced as the mechanical reliability in case of failure of P-3 has increased to $99.863 \%$ from $99.783 \%$ in S-0.

Pumps are also a critical component which should not be ignored during preparing upgrades in this case there are 4 working +2 standby pumps which results a good mechanical reliability so the is no need for upgrades.

\section{F. Step 7: Optimization Analysis}

The cost is also an essential factor in water supply systems as some expensive upgrade scenario may have little contribution to the network reliability. Therefore, optimization analysis is used to indicate the relative significance of proposed upgrade scenarios.

The following constraints are arbitrarily used to define the feasible upgrade scenarios, as shown in Figure 6:

- Minimum Water Network Reliability (assumed 99.80\%).

- Maximum Available Budget (assumed 70 Mil EGP).

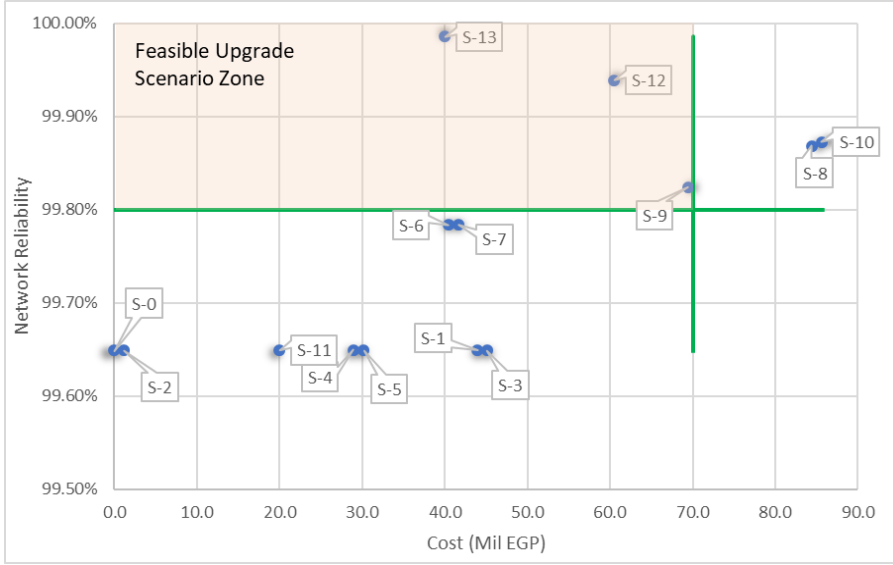

Figure 6 Monshaat Al Qanater Feasible Upgrade Scenarios

From Figure 6 it can be concluded that only 3 upgrade scenarios (S-9, S-12 \& S-13) are feasible and meet the required constrains. TABLE 8 presents the objective function of the three feasible scenarios.

TABLE 8 MONSHAAT AL QANATER FEASIBLE UPGRADE SCENARIOS

\begin{tabular}{|c|c|c|c|c|}
\hline $\begin{array}{c}\text { Upgrade } \\
\text { Scenario }\end{array}$ & $\begin{array}{c}\text { Network } \\
\text { Reliability } \\
\left(\mathrm{R}_{\mathrm{M}}\right)\end{array}$ & $\Delta \mathrm{R}_{\mathrm{M}}$ & $\begin{array}{c}\text { Cost }(\mathrm{Mil} \\
\mathrm{EGP})\end{array}$ & $\begin{array}{c}\text { CBA } \\
\left(\Delta \mathrm{R}_{\mathrm{M}} / \mathrm{Mil} \text { EGP }\right)\end{array}$ \\
\hline S-0 & $99.649 \%$ & 0.0 & 0.0 & 0.0 \\
\hline S-9 & $99.824 \%$ & $0.175 \%$ & 69.5 & 25.2 \\
\hline S-12 & $99.939 \%$ & $0.290 \%$ & 60.5 & 47.9 \\
\hline S-13 & $99.986 \%$ & $0.337 \%$ & 40.0 & 84.2 \\
\hline
\end{tabular}

From TABLE 8 it can be concluded that S-13 has the highest network reliability and CBA value and minimum cost which reflects that it is the optimum upgrade scenario in case of all objective function, S-12 and S- 9 are ranked second and third respectively.

\section{CONCLUSIONS AND RECOMMENDATIONS}

Reliability of water distribution systems is generally overlooked in design. A simplified 7-step approach is developed for the assessment of water distribution systems reliability, as follows:

Step 1: Build Hydraulic Model.

Step 2: Calculate Component Availability.

Step 3: Calculate Hydraulic Reliability.

Step 4: Calculate Mechanical Reliability.

Step 5: Calculate Network Reliability.

Step 6: Define Upgrade Scenarios.

Step 7: Optimization Analysis.

The above approach is applied to a large water distribution system in Egypt namely Monshaat Al Qanater distribution network. From the conducted analysis the following can be deducted:

- Single supply pipeline present a weak link in the distribution network which should be avoided as possible.

- Network Loops should be balanced as possible in terms of hydraulic capacity in order to maintain good hydraulic performance in case of failure of any link in the loop.

- Pumps are also a critical component which should not be ignored during preparing upgrades. In general, increasing number of working pumps and percentage 
of standby pumping capacity improve network reliability.

- Optimization analyses should be carried out to select the optimum upgrade scenario, as some expensive upgrade scenario may have little contribution to the network reliability.

- If target reliability cannot be achieved by network upgrade scenarios then water storage at demand points is recommended. Network reliability can also be improved by, reducing the break rate by preventive maintenance of the system components or using high quality of pipe materials and pumps.

\section{REFERENCES}

[1] A. Kaufmann, D. Grouchko and R. Croun, "Mathematical models for the study of the reliability of systems," Academic,, New York, US, 1977.

[2] M. Cullinane, K. Lansey and L. Mays, "Optimization availabilitybased design of water distribution networks," Journal of Hydraulic Engineering, vol. 118, no. 3, pp. 420-441, 1992.

[3] I. Goulter, "Analytical and simulation models for reliability analysis in water distribution systems," In: Cabrera E, Vela A (eds) Improving efficiency and reliability in water distribution systems. Kluwer Academic Publishers, 1995.

[4] M. A. Al-Zahrani and J. L. Syed, "Evaluation of municipal water distribution system reliability using minimum cut-set method," Journal of King Saud University - Engineering Sciences, vol. 18, no. 1, pp. 67-81, 2005

[5] A. Ostfeld, "Reliability analysis of water distribution systems," Journal of Hydroinformatics, vol. 6, no. 4, pp. 281-294, 2004

[6] A. Gheisi, M. Forsyth and M. and Gh. Naser, "Water Distribution Systems Reliability: A Review of Research Literature," Journal of Water Resources Planning and Management, vol. 142, no. 11, 2016.

[7] Goulter, "Analytical and simulation models for reliability analysis in water distribution systems," Kluwer Academic Publishers, Valencia, Spain, 1995

[8] K. Awumah, I. Goulter and S. K. Bhatt, "Entropy-based redundancy measures in water-distribution networks," Journal of Hydraulic Engineering, vol. 117, no. 5, pp. 595-614, 1991.

[9] Prasad, T. Devi and Park, Nam-Sik, "Multiobjective Genetic Algorithms for Design of Water Distribution Networks," Journal of Water Resources Planning and Management, vol. 130, no. 1, pp. 7382, 2004.

[10] Dziedzic, Rebecca and Karney, Bryan W., "Performance Index for Water Distribution Networks under Multiple Loading Conditions," Journal of Water Resources Planning and Management, vol. 142, no. $1,2016$.
[11] N. Trifunovic, "Pattern Recognition For Reliability Assessment Of Water Distribution Networks," Ph.D. dissertation, UNESCO-IHE Institute for Water Education, Delft Univ. of Technology, ISBN 978-0-415-62116-8, Delft, the Netherlands, 2012

[12] L. Mays and Y.-K. Tung, "Hydrosystems Engineering and Management," McGraw-Hill Book. Co. ISBN 0-07-041146-8, New York, US, 1992.

[13] Y. Kleiner and B. Rajani, "Comprehensive review of structural deterioration of water mains : statistical models," Urban Water, vol. 3, pp. 131-150, 2001

[14] Z. Liu, Y. Kleiner, B. Rajani, L. Wang and W. Condit, "Condition Assessment Technologies for Water Transmission and Distribution Systems," Environmental Protection Agency, U.S., 2012.

[15] A. Scheidegger, J. P. Leitao and L. Scholten, "Statistical failure models for water distribution pipes - a review from a unified perspective," Water Research, vol. 83, pp. 237-247, 2015.

[16] U. Shamir and C. Howard, "An Analytic Approach to Scheduling Pipe Replacement," Jornal of AWWA, no. 71, pp. 248-258, 1979.

[17] T. M. Walski and A. Pelliccia, "Economic Analysis of Water Main," Journal of AWWA, vol. 74, no. 3, pp. 140-147, 1982

[18] R. M. Clark, C. L. Stafford and J. A. Goodrich, "Water Distribution Systems: A Spatial and Cost Evaluation," Journal of Water Resources Planning and Management, vol. 108, no. WR3, pp. 243 256, October 1982

[19] Y. Kleiner and B. Rajani, "Forecasting Variations and Trends in Water-Main Breaks," Journal of Infrastructure Systems, vol. 8, no. 4, pp. 122-131, December 2002

[20] L. Parvizsedghy, I. Gkounti, A. S. T. Zayed, M. Alsharqawi, H. E. Chanati, M. El-Abbasy and F. Mosleh, "Deterioration Assessment Models for Water Pipelines," International Journal of Civil and Environmental Engineering, vol. 11, no. 7, 2017.

[21] D. R. Cox, "Regression Models and Life Tables," Journal of Royal Statistic Society, vol. 34, no. B, pp. 187-220, 1972

[22] I. C. Goulter and A. V. Coals, "Quantitative Approaches to Reliability Assessment in Pipe Networks," Journal of Transportation Engineering, vol. 112, no. 3, pp. 287-301, 1986.

[23] Y. C. Su, L. W. Mays, N. Duan and K. E. Lansey, "Reliability based optimization model for water distribution systems," Journal of Hydraulic Engineering., vol. 114, no. 12, pp. 1539-1556, 1987.

[24] S. A. Andreou, D. H. Marks and R. M. Clark, "A new methodology for modelling break failure patterns in deteriorating water distribution systems: Theory," Advance in Water Resources, vol. 10, no. 1 , pp. 2-10, 1987.

[25] A. G. Constantine, J. N. Darroch and R. Miller, "Predicting underground pipe failure," Australian Water Works Association, 1996.

[26] Y. Kleiner and B. Rajani, "I-WARP: Individual water mAin renewal planner," Drinking Water Engineering and Science, vol. 3, no. 1, pp. 71-77, 2010

[27] A. Scheidegger, L. Scholten, M. Maurer and P. Reichert, "Extension of pipe failure models to consider the absence of data from replaced pipes," Water Research, vol. 47, no. 11, pp. 3696-3705, 2013. 